BJHS: Themes 1: 1-11, 2016. C British Society for the History of Science 2016. This is an Open Access article, distributed under the terms of the Creative Commons Attribution-NonCommercialShareAlike licence (http://creativecommons.org/licenses/by-nc-sa/4.0/), which permits noncommercial re-use, distribution, and reproduction in any medium, provided the same Creative Commons licence is included and the original work is properly cited. The written permission of Cambridge University Press must be obtained for commercial re-use.

doi:10.1017/bjt.2016.12

\title{
Science of giants: China and India in the twentieth century
}

\author{
JAHNAVI PHALKEY* AND TONG LAM**
}

\begin{abstract}
How might one tell the histories of China and India - two countries that have come to be seen as twenty-first-century giants? How might one tell of how they look to the world and to each other? In this issue we juxtapose, connect and compare the two. Ours is an attempt at a historiography of twentieth-century modernity in China and India beyond the encouragement of Euro-American historiography. We seize this opportunity provided by the contemporary engagement and concern with the two countries to reinterpret the narratives of their twentieth-century transformation, which are far from settled at the moment. We bring historical knowledge to speak usefully to the excitement, anxiety and aspiration around science and technology in China and India. We bring the same to speak meaningfully to the cynicism, admonition and expectations that the world has of them. We use China and India as a method of exploring new historiographical questions of science. We are invested in extending the relevance of studying China and India to the world at large through connections, references and juxtaposition, and by raising questions that, on the one hand, expose the limits of the EuroAmerican experience and, on the other, open up the intellectual and historiographical space for narratives and theoretical frameworks that are not tied to geopolitical significance. This paper sets out these issues and introduces the papers of the collection.
\end{abstract}

Not very long ago, Jack Goody, the anthropologist, posed a question: 'How is it that China and India, apparently without the development of "capitalism", which was Western, are now challenging the West for supremacy in so many fields?'

* India Institute, King's College London, WC2R 2LS, UK. Email: jahnavi.phalkey@kcl.ac.uk.

** University of Toronto, 100 St George Street, Sidney Smith Hall, Toronto, Ontario, M5S 3G3, Canada. Email: tong.lam@utoronto.ca.

The papers in the issue are a product of collaboration and conversation over four years generously funded by the Indian European Advanced Research Network, Nantes. The first workshop was funded by York University and the Situating Science Strategic Knowledge Cluster, Canada. We acknowledge the generous intellectual support we have received from Jon Agar, Raghavendra Gadagkar, Ludmilla Jordanova, Samuel Jube, Sunil Khilnani, John Krige, Bill Leslie, Bernard Lightman, Joachim Nettelbeck, Srinath Raghavan, Dominic Sachsenmaier, Tansen Sen, Grace Yen Shen, Wang Hui, Jon Wilson and Roland Wittje. Finally, we thank the Wissenschaftskolleg zu Berlin where we (Lam and Phalkey) were fellows in 2013-2014.

We would like to thank the following institutions for hosting our workshops: Department of Humanities, Bethune College, York University, Canada (2011); India Institute, King's College London, UK (2012); Tsinghua Institute for Advanced Study in Humanities and Social Sciences, Beijing, China (2013); and finally the Centre for Contemporary Studies, Indian Institute of Science, Bangalore, India (2015). Many thanks to Pauline Boudant, Bitasta Das, Matthieu Forlodou and Nilanjan Sarkar for their support in keeping the project together.

1 Jack Goody, 'Asia and Europe', History and Anthropology (2015) 26, pp. 263-307, 263. 
Not everyone is convinced of the challenge. Even when China and India are seen as emerging powers, there are many different ways in which this challenge is described and explained. Goody finds an explanation for the rise of at least China in the sameness and overlap of Eurasian history in the early modern period. ${ }^{2}$ Others locate the beginnings of this rise in the struggle for political and intellectual independence during the middle decades of the twentieth century. ${ }^{3}$ Magazines such as Science and Nature have dedicated sections to China and India in the last decade to help their readers make sense of the socalled rising science powers. The Royal Society published a report making clear that the production of scientific knowledge had now gone global, and China and India were places to watch. ${ }^{4}$ Historians of science responded too. Bernard Lightman, editor of the history-of-science journal Isis, commissioned two Focus sections on China and India. The journal did not carry any other country-focused section. ${ }^{5}$

We wish to seize this opportunity provided by the contemporary engagement and concern with the two countries to reinterpret the narratives of their twentieth-century transformation, which are far from settled at the moment. The middle decades of the last century witnessed an intensity of transformation and a focus on industrialization and economic growth that set both on the path to what has been called catching up. Their own stories of the mid-twentieth-century origins of their current formation, the silences on some aspects and the attentiveness to others, are of primary interest to us.

In this issue we juxtapose, connect and compare the two giants. Ours is an attempt at a historiography of twentieth-century modernity in China and India beyond the encouragement of Euro-American historiography. We unravel histories and networks of science and engineering through diverse practices, and we locate historical energies that produced the modern in the two countries but on an international plane.

Writers at The Economist appear convinced of the long road that China must travel before leading the world, but they enlist the projects that show why Goody can frame China and India as challenges to the West:

The world's largest single-aperture radio telescope, being built in Guizhou province, is due to open in September. The Five-hundred-metre Aperture Spherical Telescope (Tianyan, in Chinese) dwarfs all other such instruments ... And it is expanding 25 -fold its dark-matter-

2 For a more up-to-date analysis of how China and Europe contributed to the rise of capitalism see Kenneth Pomeranz, The Great Divergence: China, Europe, and the Making of the Modern World Economy, Princeton, NJ: Princeton University Press, 2001.

3 Pankaj Mishra, From the Ruins of Empire: The Revolt against the West and the Remaking of Asia, London: Penguin, 2003. Ramachandra Guha, Makers of Modern Asia, Cambridge, MA: Belknap, 2014.

4 Among others see 'Science in India', special in Nature, 13 May 2015, at www.nature.com/news/india-1. 17456. 'The Chinese research paradigm: addressing global science issues', sponsored supplement of Science (19 December 2014) 346(6216). The Royal Society, Knowledge, Networks, and Nation: Global Scientific Collaboration in the Twenty First Century, London: Royal Society, 2011, available at https://royalsociety. org/ /media/Royal_Society_Content/policy/publications/2011/4294976134.pdf. All accessed 4 June 2016.

5 'Focus: science and modern China', Isis (2007) 98(3), pp. 517-596; and 'Focus: science, history, and modern India', Isis (2013) 104(2), pp. 330-380. The journal carried a region-focused section: 'Focus: global currents in national histories of science: the "global turn" and the history of science in Latin America', Isis (2013) 104(4), pp. 773-817. See also China, India, and the United States, special issue of Technology in Society (2008) 30(3-4). 
investigating Jinping underground laboratory, in Sichuan province, making that the world's largest subterranean lab. ${ }^{6}$

India's strength apparently lies elsewhere:

India has already had one technology revolution. In the 1980s middle-class engineers from a dirt-poor socialist India somehow persuaded Western firms to outsource their back-office functions and bits of their IT operations to the subcontinent. Thus began a three-decade-long boom ... The cultural impact of all this has been huge. ${ }^{7}$

This was only a couple of years earlier when they covered the Indian Mars mission: 'Its Mars mission may be cheap by American (or Chinese) standards, at just $\$ 74 \mathrm{~m}$, but India's overall space programme costs roughly $\$ 1$ billion a year. That is more than spare change, even for a near \$2-trillion economy."8

How might one tell the histories of these two countries that have come to be seen as twenty-first-century giants, of how they look to the world and to each other? How do we bring historical knowledge to speak usefully to the excitement, anxiety and aspiration around science and technology in China and India? How do we bring the same to speak meaningfully to the cynicism, admonition and expectations that the world has of them? We hope to use China and India as a method to explore new historiographical questions of science. We seek to rethink India through China, China through India, and aspects of global history through China and India. ${ }^{9}$ This is the leitmotif of our collaboration.

Histories of both China and India as our generation of historians of science have understood them - and we are no different - are mostly mediated through Western scholarship on the two, often in the English language. We came to this collaborative exercise with that awareness and with substantial archival research behind us. Apart from the rich historical detail, this issue's main contribution is methodological; our goal is to experiment with historiography and think of strategies to overcome this mediation at least to some extent through the juxtaposition of China and India.

Our histories are of two nations, China and India. However, we begin not with their stability but with their historical agency. Analytically, with our historical actors we work with, against and beyond their ideas of nation. There are the politics of the subjectivities of our historical actors, and there are the politics of our own subjectivities. Our project might embody a global and deep collaboration, and this issue is the outcome of our spirited conversations in Toronto, London, Beijing and Bangalore. Even as we wish to rescue

6 'Schrödinger's panda', The Economist, 4 June 2016, at www.economist.com/news/science-andtechnology/ 21699898-fraud-bureaucracy-and-obsession-quantity-over-quality-still-hold-chinese, accessed 4 June 2016.

7 'The screen revolution', The Economist, 13 March 2016, at www.economist.com/news/business/21573551meet-next-generation-indian-technology-firmsand-obstacles-they-face-screen, accessed 4 June 2016.

8 'How can poor countries afford space programmes?', The Economist, 4 November 2013, at www. economist.com/blogs/economist-explains/2013/11/economist-explains-0, accessed 4 June 2016.

9 Wang Hui, The Politics of Imagining Asia (ed. Theodore Huters), Cambridge, MA: Harvard University Press, 2011. See also Kuan-hsing Chen, Asia as Method: Toward Deimperialization, Durham, NC: Duke University Press, 2010; and Warwick Anderson, 'Asia as method in science and technology studies', East Asian Science, Technology and Society: An International Journal (2012) 6, pp. 445-451. 
histories from the nation, ${ }^{10}$ we remain acutely aware of the commitment of our historical actors to the futures of these ideas and how residues of those remain also in our analytical apparatus.

We bring together histories of science and technology in China and India during the twentieth century; we are not aware of a comparable effort. Among our first goals is to move beyond comparison. More often than not, comparisons tend to idealize one and to essentialize both. ${ }^{11} \mathrm{We}$ aim, instead, to juxtapose and connect in order to think about China through India and India through China, to identify, as Bin Wong would have it, the limits of Western experience and to locate the boundaries around knowledge about the two countries - both, in their current formation, products of the turbulent twentieth century. In turn we question and refocus on the received wisdom about the twentieth century in general, and about science and technology in particular. ${ }^{12}$

This issue expands the historiographies of science and technology not merely to include the experiences of the global South, but also to question the capability of current historiography to address these experiences at all. We do not want to begin from the canon of history of science to bring India and China into the fold. We begin instead with listening to the concerns of our historical actors, what they call - often indistinguishably - science and engineering/technology. Even when such phenomena resonate with what scholars of science and technology studies (STS) have come to call techno-science, we do not begin with given concepts. Our aim has been to create pathways to new concepts and tools to craft histories that make sense of experience, not as measure or evaluation or assessment of those considered outside its norm.

Historians of Europe and North America often mistake the geopolitical significance of the regions they work on for the significance of their work itself. A similar accusation could be made of us: China and India are now seen as significant global players. There is no denying that the opportunity to publish a collection of this kind is a product of our time. We would like to use this opportunity and the space it has created to raise questions about what even makes a space like this possible. We would like, in the continuation of our work, to understand the politics of this attention and how that speaks to Chinese and Indian experience of science and technology.

Historiographies of science in China and India thus far have been, primarily, reflections on difference. Historiography of medicine, especially, has folded in with relative ease into that framework. We believe ours is a slightly different task given that science and engineering practices in the twentieth century seldom diverge into distinct ontologies as they do in medicine. Histories of Ayurveda and Chinese traditional medicine fit well within this larger framework of difference providing neat non-Western systems

10 Prasenjit Duara, Rescuing History from the Nation: Questioning Narratives of Modern China, Chicago: The University of Chicago Press, 1995.

11 Micol Siegel, 'Beyond compare: comparative method after the transnational turn', Radical History Review (Winter 2005) 91, pp. 62-90; Abdelhamid Ibrahim Sabra, 'Situating Arabic science: locality versus essence', Isis (1996) 87, pp. 654-670. See also the discussion of comparative studies in Gayatri Chakravorty Spivak, 'Rethinking comparativism', New Literary History (2009) 40, pp. 609-626.

12 Bin Wong, China Transformed: Historical Change and the Limits of European Experience, Ithaca, NY: Cornell University Press, 2000. 
that confront or encounter Western biomedicine. Scholars have written about these complicated histories with increasing nuance; however, our problematic is placed where historiography of medicine began to inform the framework also of science and technology. History of science and technology in these countries and, arguably, in the global South is often reduced to ontological confrontations with the assumption that these are somehow not merely different but also incommensurable and at times illegible.

Implicit in this conception and production of irreducible difference is also a notion of potential sameness that seeks to violently transform social relationships and historical processes into a universalizing narrative affirming the superiority of Euro-American accomplishments, especially in science and technology. That we continue to regard Shenzhen as nothing but an oversized sweatshop even though it has become a hub of global start-ups highlights the urgency of using China and India as conceptual sites to rethink the history of science and technology. Spatial outcomes are temporally mapped. China and India, no wonder, are always catching up.

\section{On shared problematics and divergence}

It is productive to think about twentieth-century China and India together, first and foremost, because they have compared themselves to each other in the middle decades of the twentieth century. Second, and equally important, political and industrial leadership in the two countries puts science and technology at the heart of their transformation into new regimes. Finally, both China and India operated in the global context of colonialism and imperialism in the first half of the twentieth century.

In this issue, we have explored some of this shared experience by locating the Indian and Chinese abroad, especially in the West and in the Soviet Union where relevant. We also locate the differentiated presence of the West in China and India. While the site details tell different stories, we can meaningfully identify the Chinese and Indian readings of especially European history in the early half of the twentieth century, and of American and Soviet history in the latter half. And we identify shared practices amid seemingly unbridgeable ideological divides.

To begin with, China and India were the Orient of the imperial age. As such, the twentieth century saw political leadership in both countries set out decisively to overcome that description with the desire to become equals among nation states of significance, while seeking to revive and reinvent their civilizational grandeurs. At the same time, both had to come to terms with their respective relationship with the colonial question. The Indian Empire was ruled by the British, and China was partially subjugated to European and Japanese imperialist rules. In order to prevent future foreign conquest, leaders of both countries felt compelled to embrace Western-style modernizing projects.

If China was closely aligned with the Soviet Union for the first decade and a half after 1949 , India was less committed at first and realigned around the same time as the SinoSoviet rift to a non-aligned politics that emerged in 1955. Unsurprisingly, this early Cold War era witnessed regular traffic among scientists and engineers of the countries. Up until the Sino-Indian border conflict of 1962, the two nations continued to cautiously 
share similar commitments to science, economic growth and the idea of social betterment. Both countries had to sustain very large populations while trying to achieve speedy development. Both held ambitions to become global players in what was largely seen as a binary geopolitical order of the Cold War. Above all, as we said earlier, both had tremendous faith in science and technology as the key to nation-building projects. Nonetheless, military belligerence led to great distance and distrust when compared to the exchanges and references they made to each other in the early decades of Independence and the establishment of the People's Republic.

Another significant divergence between the two is their political systems. This aspect of the two countries calls for a nuanced discussion that is well beyond the scope of this issue. However, at least through the lens of science and technology, we find that the divergence may not be as pronounced, and at most times not along the fault lines of ideology, as might be assumed to be the case.

The two nations also diverge on mobility. Until recently, many more Indian scientists and engineers were travelling back and forth to the Euro-American world when compared to their Chinese counterparts. As a result, the role of the diaspora has been significant in the development of science and engineering in India. ${ }^{13}$ In the 1980 s and 1990s, the belated influx of a massive Chinese diaspora was still mostly related to investment in the manufacturing sector. Nonetheless, the gap has been narrowed drastically in recent years as a number of overseas Chinese scientists, in addition to returned students previously sent by the government, are working in China. Needless to say, the mobility of experts, but also of ideas, practices and even capital, is central to our concern of focusing on both global circulation and site-specificities in the rethinking of the history of science and technology.

If for a significant part of the twentieth century the Chinese and Indian agenda was to implement big-science projects for economic growth, then that agenda has now been supplemented by the call for innovation. In other words, compared to the differences in political economy and manufacturing in the earlier period, state-led privatization - state capitalism - in both countries since the late 1970s has brought them closer ideologically and geopolitically. And even if planning and large-scale social-engineering projects remain a part of the governing logic, we discover that contemporary science, economic growth and social order are increasingly articulated in strikingly similar terms of innovation, entrepreneurship and other new liberal initiatives.

\section{Temporality}

In many ways, the Euro-American past and present are the imagined futures of China and India. This has been and continues to be heavily contested in both countries. If

13 Ross Bassett, The Technological Indian, Cambridge, MA: Harvard University Press, 2016; Bassett, 'MIT-trained swadeshis: MIT and Indian nationalism, 1880-1947', Osiris (2009) 24, pp. 212-230; Zuoyue Wang, 'The Cold War and the reshaping of transnational science in China', in Naomi Oreskes and John Krige (eds.), Science and Technology in the Global Cold War, Cambridge, MA: MIT Press, 2014, pp. 343370; and Devesh Kapur, Diaspora, Development, and Democracy: The Domestic Impact of International Migration from India, Princeton, NJ: Princeton University Press, 2010. 
modernity has already had its 'authentic' incarnation in Europe, how will it repeat elsewhere but as an imitation? No wonder, then, that there has been an awareness in China and India of being held up in this imaginary waiting room of history. ${ }^{14}$ In China, communism was once thought a shortcut to modernity. What exactly they wanted to catch up with or surpass has also shifted in the last seventy years: the goals have ranged from excellence in research to GDP numbers.

The paths to catching up or to surpassing the West are not necessarily the same in China and India but both have taken up science and engineering projects that could be called the first, the largest or the least or most expensive. Like resonances of modernization theory, or at least its goals, we also find innumerable references to the much-discredited (by historians) yet still mobilized linear model that suggests that science, economic development and democratic governance always come hand in hand. If we follow this logic, then fundamental science, if properly funded, is supposed to yield economic growth, which in turn would enable democracy. By the same argument, then, scientific and economic progress cannot be secured without a free and open society. During the Cold War, when this model was mapped onto these two ancient civilizations, we were told that communist China needed to catch up with democratic India. In recent years, as China has economically surpassed India, the narrative becomes that of India catching up with China, prompting some Indian leaders to call for a more authoritarian model of governance.

In spite of the repeated failure of modernization theory or the linear model to make sense of the uneven development of the global South and the growing stagnation of the global North, it continues to evoke strong support and argument among policy makers and isolated academic quarters. Significantly, we notice that many of our historical actors, who operated under the global context of imperialism and national liberation, have also failed - if they tried at all - to dislodge the powerful narrative of progressive time that came with imperialism. Neither have they escaped from the essentialization of spatial differences that underpins the epistemology of imperialism. This argument is evoked in both China and India, where modernization was seen as a necessary formula to avert the fate of being colonized. Nonetheless, in India there was the strong dissenting voice of Mohandas Gandhi and his followers prior to Independence, an argument that was strengthened and refined again in the 1970s. In China, such a strong dissenting opinion has largely been absent. Instead, Chinese leaders and intellectuals have been unrelenting advocates of techno-scientific modernity, which is often manifested in unapologetic forms of social-engineering intervention, urbanism and high-speed growth.

All said and done, this does mean that our historical actors simply accepted the powerful idea that there is such a thing as Euro-American superiority in science and technology. Instead, they refracted and reflected on their work through a selective appropriation of Euro-American ideas and practices to define their ambitions. In their most recent formation of being part of the BRIC (Brazil, Russia, India, and China) grouping, their claim to become, to some extent, an aspirational model for parts of

14 Dipesh Chakrabarty, Provincializing Europe: Postcolonial Thought and Historical Difference, Princeton, NJ: Princeton University Press, 2000. 
Africa and Latin America puts an end to any misguided idea of universal history. In this issue, we examine both their rhetorical claims and their actions in equal seriousness.

\section{Science and the state}

We mentioned earlier that two polities diverged at their origin in the 1940s. What were the manifestations of that divergence? One would expect to find the most pronounced manifestation in aspects that concerned the state, and in our case, state patronage of science and technology.

China has a long history of sophisticated statecraft but civil and external wars limited the role of the state in the institutionalization of science in the early half of the twentieth century. Nonetheless, science flourished in what have been called semi-colonial spaces such as Beijing and Shanghai. ${ }^{15}$ In India, the British Indian government established imperial institutions to produce useful knowledge and this laid the foundations for some of the administrative and institutional infrastructure that would be developed in India after Independence.

It was in the post-war era that the pursuit of large-scale technocratic solutions to social problems gained momentum. We find that 'directed research was not incompatible with doing good science and that state patronage was not synonymous with state control'. ${ }^{16}$ China and India, alongside the Soviet Union, exemplify this scale for our discussion. They belong together in a way that is actually not that different from the Cold War narratives of divergence and convergence between the Soviet Union and the United States.

Furthermore, to the extent that the state functions as a field of knowledge and power, as Timothy Mitchell puts it, science and technology are very much part of the practices that are at the very foundation of the idea of the modern state and state power. ${ }^{17}$ Our studies similarly confirm that in spite of their differing political systems, big-science and large-scale engineering projects in both countries were pivotal to the reification of the bureaucratic nation state. Our collaboration therefore highlights the importance of following 'science in action' in the globally connected processes of state making and state transformation. ${ }^{18}$

\section{Prospectus}

Western imperialism did not only imagine Chinese and Indian cultures as exotic and incompatible - the two countries were mapped onto a hierarchical framework of

15 For a discussion of how early twentieth-century China was a laboratory of modernity see Tong Lam, $A$ Passion for Facts: Social Surveys and the Construction of the Chinese Nation-State, 1900-1949, Berkeley: University of California Press, 2011. See also Helen Tilley, Africa as a Living Laboratory: Empire, Development, and the Problem of Scientific Knowledge, 1870-1950, Chicago: The University of Chicago Press, 2011.

16 John Krige, 'Concluding remarks', in Oreskes and Krige, op. cit. (15), pp. 431-441, 431.

17 Timothy Mitchell, 'Society, economy and the state effect,' in George Steinmetz (ed.), State/Culture: StateFormation after the Cultural Turn, Ithaca, NY: Cornell University Press, 1999, pp. 76-97.

18 Bruno Latour, Science in Action: How to Follow Scientists and Engineers through Society, Cambridge, MA: Harvard University Press, 1987. 
difference. The massive body of writing on the history of Chinese science and medicine by the British sinologist Joseph Needham is one such example. Leon Rocha shows that in order to include China and India in the history of 'universal medicine', Needham had to place the two countries within an existing and primarily European history of science and technology based on a schema of difference. For example, Needham contended that China was 'proto-scientific' and that India was even less scientific. Such an approach, relegating the scientific knowledge of non-Western societies to the status of protoscience or ethno-science, and holding Western science as science, on the one hand has failed to appreciate the Chinese and Indian histories of science and medicine on their own terms, and on the other has neglected the crucial ways in which non-Western worlds participate in the production of scientific knowledge both conceptually and empirically. This latter aspect is taken up by Fa-ti Fan and John Mathew, who illustrate how the local worlds were used to construct respective knowledge of natural history for the British Empire and of the Chinese nation in the early twentieth century. In short, they show that imperial frontiers, rather than being backward, were the laboratories of science and circuits of knowledge.

If the so-called peripheral spaces were central to the formation of the empire's selfknowledge, one also sees how the flip side of this logic played out within the new Chinese and Indian nation states in the post-war era. In their study of endangered snow leopard and contemporary conservation politics, Michael Lewis and E. Elena Songster explain how restricted border zones between the two nations have rendered snow leopards concentrated in the region largely invisible in the two countries' national scientific and geographical imaginations. Subsequently, unlike 'Chinese' pandas and the 'Indian' tigers that are surrounded by national rhetoric, snow leopard conservation has mostly been driven by domestic and international NGOs.

Just as differences in geopolitical space have given rise to different narratives of natural history and conservation science, Pin-Hsien Wu too argues that contemporary conceptions of nature and environmental politics diverge in these two countries precisely because of their specific historical and sociopolitical circumstances. Based on two cases of 'coal capitals', Wu's discussion of pollution reminds us of the widespread ecological devastation and human toll behind these industrial undertakings in the name of development.

Whereas coal conjures up the massive industrial undertakings in post-war China and India, agricultural modernization as envisioned by United States scientists seems to take on a softer image. As Madhumita Saha and Sigrid Schmalzer argue, United States experts and engineers championed their notion of 'green revolution', which highlighted the depolitical and technocratic nature of their interventions as opposed to the 'red revolution' of communism. Nonetheless, instead of just focusing on technological transfer, the authors trace the practices of science and emphasize the important role of Chinese and Indian scientists in shaping the imported techno-scientific model.

In a similar vein, Jahnavi Phalkey and Zuoyue Wang tackle the practice of top-down intervention by examining the early history of comprehensive five-year plans for science and technology based on the Soviet model of national planning. Here, too, they remind 
us that China and India had plenty of common challenges and concerns, as well as shared inspirations and aspirations, that have often been overlooked by the rhetoric of the Cold War. Diganta Das and Tong Lam, meanwhile, analyse how China and India have moved considerably beyond the earlier practice of planning and arrived at a whole different kind of 'green' development in the new era of global capitalism. Specifically, they show that a global network of science parks that are consistent with the logic of transnational capital in recent decades has replaced the heavy-industrial zones of the Cold War era as the new growth engines. They further contend that these science parks, more than just a space for science, are often marketed as utopian living spaces for urban elites in the larger neoliberal symbolic economy.

As science is used to envisage new urban space and mould middle-class consumer subjects, science fiction is key to our common imagination of the future. In their conversation about the place of science fiction in the histories of science and technology in China and India, Anna Greenspan, Anil Menon, Kavita Philip and Jeffrey Wasserstrom playfully reverse the trope of 'catching up' and contend that China and India are hardly backward. Drawing on examples of speculative fictions and a range of cultural practices, their conversation challenges the prevailing cultural narrative of a unitary and linear notion of progress, and raises the prospect that places such as Bangalore and Shenzhen, rather than Silicon Valley, are at the forefront of innovation.

This issue takes the interactions within the global South seriously. Arunabh Ghosh's study of the South-South scientific exchange between China and India in the history of statistics is one such example. By decentring the Soviet Union and the United States as the sources of scientific knowledge, he reveals an alternative history of statistical science that would otherwise be buried in the binary logic of the Cold War. Also, the global South is not a territorial concept. Asif Siddiqi further illustrates why spatial dynamics of scientific knowledge production are not about simply shifting to China and India as our research location. The production of scientific knowledge as examined by Siddiqi was situated in a global network of sites that involved the village of Thumba in the southern tip of India; the MIT campus in Cambridge, Massachusetts; the Chinese Academy of Science in Beijing; and the Soviet city Dnepropetrovsk. In sum, scientific ideas do not just circulate, but are generated in the very process of circulation and global collaboration.

\section{Coda}

In the end, what has emerged from our conversations and papers is a reassuringly contingent history against a set of global imperatives such as the Cold War, empire, nationalism, socialism and capitalism. People, ideas, artefacts move around in an unpredictable manner. Political claims are more distinct than the processes they purport to draw their conclusions from or to represent. These claims often remain unresolved. And sometimes they are resolved in unexpected ways.

In both China and India goals and aspirations far exceed any realistic assessment of capability. There is, as George Perkovich puts it, an entitlement to greatness that both 
seem to exhibit. ${ }^{19}$ This preoccupation with a sense of greatness, however tenuous, is invested with great passion in both. At the heart of this passion is the desire to question the self-confidence of the claim around the rise and supremacy of the West. The specific claim to greatness comes from reference to a civilizational history that allows both, to some extent, to overcome the politics, at least at home, of being geopolitically superseded by the West.

One tension, therefore, at the heart of any attempt to write contemporary history of these two giants that are poised to change the world is, on the one hand, the claim to enduring earthly presence, to long unbroken historical processes. On the other hand, at the same time as they both speak from a deep historical past, they also claim to have become rapidly changing and advancing nations that have been completely transformed during the twentieth century. Their political systems are now homologous with the world system of nation states, and their economies are inseparable from the global economy. Both narratives have power, even as both are only partially accurate. Our focus on the twentieth century has opened up this very space, when the two narratives come into their own, allowing us to unsettle both - the ideas of enduring tradition and the entitlement to greatness that nationalism has afforded both China and India. When, in China, the political leadership travels from the Ming dynasty to the space age without a breath in between, the twentieth century, the troubled century of difficult transformation for both, is brushed over. Political leadership in India is now beginning to do the same. In this issue we open up aspects of precisely that difficult transformation.

Science and technology in China and India during the twentieth century, like elsewhere, are about social change, economic growth and even national survival. We are aware that there is today a politics to imagining especially China and, to an extent, India: it is the politics of potential accompanied by fears of their divergence. It is our hope to have shown that the geopolitical statuses of countries are not self-evident frameworks, nor do they provide useful analytical categories for historical work. We are interested in specificity, and it is this very commitment to specificity that stops us from making generalized observations about the global South. At the same time, we are invested in extending the relevance of studying China and India to the world at large through connections, references and juxtaposition, and by raising questions that, on the one hand, expose the limits of the Euro-American experience, and on the other open up the intellectual and historiographical space for narratives and theoretical frameworks that are not tied to geopolitical significance.

19 George Perkovich, 'The measure of India: what makes greatness?', in Seminar: The Monthly Symposium, at www.india-seminar.com/2003/529/529 george perkovich.htm, accessed 4 June 2016. 